\title{
The Role of Friends' Disruptive Behavior in the Development of Children's Tobacco Experimentation: Results from a Preventive Intervention Study
}

\author{
Pol A. C. van Lier • Anja Huizink • Patricia Vuijk
}

Published online: 7 August 2010

(C) The Author(s) 2010. This article is published with open access at Springerlink.com

\begin{abstract}
Having friends who engage in disruptive behavior in childhood may be a risk factor for childhood tobacco experimentation. This study tested the role of friends' disruptive behavior as a mediator of the effects of a classroom based intervention on children's tobacco experimentation. 433 Children (52\% males) were randomly assigned to the Good Behavior Game (GBG) intervention, a universal preventive intervention targeting disruptive behavior, and facilitating positive prosocial peer interactions. Friends' disruptive behavior was assessed from age 7-10 years. Participants' experimentation with tobacco was assessed annually from age 10-13. Reduced rates in tobacco experimentation and friends' disruptive behavior were found among GBG children, as compared to controls.
\end{abstract}

\section{P. A. C. van Lier $(\bowtie)$}

Department of Developmental Psychology,

VU University Amsterdam,

Van der Boechorststraat 1, 1081 BT,

Amsterdam, the Netherlands

e-mail: pac.van.lier@psy.vu.nl

P. A. C. van Lier $\cdot$ P. Vuijk

Department of Child and Adolescent Psychiatry,

ErasmusMC-Sophia,

Rotterdam, the Netherlands

\section{A. Huizink}

Research Institute of Child Development and Education, University of Amsterdam,

Amsterdam, the Netherlands

\section{A. Huizink}

Behavioral Science Institute, Radboud University Nijmegen,

Nijmegen, the Netherlands

\section{A. Huizink}

Research Institute on Addiction (IVO),

Rotterdam, the Netherlands
Support for friends' disruptive behavior as a mediator in the link between intervention status and tobacco experimentation was found. These results remained after controlling for friends' and parental smoking status, and child ADHD symptoms. The results support the role of friends' disruptive behavior in preadolescents' tobacco experimentation.

Keywords Friends' disruptive behavior .

Tobacco experimentation - Preventive intervention .

\section{Childhood}

Around age 10 years children from the general population start experimenting with tobacco and the percentage of children experimenting increases rapidly thereafter. For instance, in both the US and the Netherlands, approximately $10-15 \%$ of 10 -to- 11 -year-old children reported experimentation with tobacco, a percentage that increases to approximately $35 \%$ at age 13 years (Monshouwer et al. 2004; Mowery et al. 2004). Experimentation with tobacco at this age places children at risk for regular smoking at later ages (Costello et al. 1999; Patton et al. 2006; Robinson et al. 2004), but also at risk for alcohol use (Clark 2004) and illicit drug use (Korhonen et al. 2008).

Studies have focused on the role of friends in the initiation and further development of tobacco use. For instance, a study among US youths aged 11-14 years found that among those who smoke, the odds of having friends who also smoke is increased 7.12 times when compared to youths who don't smoke (Mowery et al. 2004). To illustrate, having parents or caretakers who smoke increased the odds of youths smoking by 2.88 (Mowery et al. 2004). This study aimed at exploring the role of friends' behavioral characteristics in the early years of elementary school on children's tobacco experimentation from age 10 13 years. Specifically, we aimed at testing this link using a 
randomized controlled preventive intervention study, the Good Behavior Game (GBG; Barrish et al. 1969; Dolan et al. 1989). We explored whether having friends with lower levels of disruptive behavior, as found among children who received the GBG intervention, mediated the program's impact on children's tobacco experimentation.

\section{Friends' Disruptive Behaviors and Children's Tobacco Experimentation}

In search of the identification of risk factors for early experimentation with tobacco, influences from friends during middle childhood have been studied. Indeed, friends do influence children's smoking habits (Kobus 2003; Mowery et al. 2004; Prokhorov et al. 2006), possibly through processes of imitation, social reinforcement, and by making cigarettes available (Hoffman et al. 2006). The actual imitation by children of friends' smoking behavior is less likely in the early years of elementary school, as most children during middle childhood have not experimented with tobacco. However, some elementary school children do affiliate with friends who engage in disruptive behavior (Snyder et al. 1997; Snyder et al. 2005; van Lier and Koot 2008; van Lier et al. 2005a; Vitaro et al. 2007). Having friends who are disruptive has not only been found to be a risk factor for the continuation of children's disruptive behavior (Boivin et al. 2005; van Lier et al. 2005a; Vitaro et al. 2007; Vitaro et al. 2001), but also a predictor of tobacco use (Dishion and Owen 2002; Fergusson et al. 2002; Fite et al. 2008). Thus, during middle childhood, it may not be the actual imitation of friends' smoking behavior or reinforcement of smoking behavior per se which triggers starting experimentation with smoking. Rather, having friends with disruptive behaviors problems may, via emphasis on, or modeling and selective reinforcement of risky behavior create a context in which early experimentation with tobacco is likely.

\section{Effects of GBG on Children's Tobacco Experimentation and Friends' Disruptive Behaviors}

Given the negative outcomes associated with early tobacco experimentation, several studies have been directed at its prevention. These studies have found that children's experimentation with tobacco use may be reduced by school-based interventions. In a previous study on the sample used in the present study, it was shown that GBG children less frequently engaged in tobacco experimentation over the ages of 10-13 years (van Lier et al. 2009). US based studies using the GBG showed that childhood reductions in tobacco use among GBG children (Kellam and Anthony 1998) persisted into adolescence (Furr-Holden et al. 2004; Storr et al. 2002) and even young adulthood (Kellam et al. 2008). For instance, in young adulthood, the proportion of GBG children who smoked regularly was $6 \%$, compared to $14 \%$ among control-group children (Kellam et al. 2008).

It is important to note that the GBG is not a preventive program aimed at the reduction of substance use. Rather, the GBG is a classroom management program, with as primary purpose the prevention of disruptive behavior problems, such as conduct problems or symptoms of ADHD, among elementary school children. The program aims to create a positive and predictable school environment, by improving classroom structure, facilitating prosocial peer interactions, and by focusing on, and systematically rewarding appropriate behavior. Specifically, in order to improve classroom peer relations, in the GBG disruptive and non-disruptive children work together in teams, and teams as a whole are rewarded for endorsing positive and prosocial classroom behavior. In this way the GBG tries to break the cycle of negative peer experiences and selective affiliation with deviant peers which characterizes children with behavior problems.

Thus, by facilitating prosocial peer relations the GBG aims to reduce children's disruptive behaviors. When this aim is achieved indeed, the GBG may reduce children's risk of connecting with friends who engage in disruptive behavior. If having friends with high levels of disruptive behavior in elementary school is truly predictive of tobacco experimentation, reduction of these friends' disruptiveness would result in lower levels of tobacco experimentation. One of the processes through which the program resulted in reduced rates of children's problem behavior was through improved peer relations, indicated by improved peer acceptance, and reduction of friends' disruptive behavior (van Lier et al. 2005b; Witvliet et al. 2009). Given these previous findings and the evidence for a role of friends' disruptiveness in the prediction of tobacco experimentation, we aimed at testing whether reduction of friends' disruptive behavior, as found among GBG children, explained why GBG children become less likely to experiment with tobacco.

\section{Important Controls}

Apart from having friends with high levels of disruptive behavior children's own disruptiveness has been shown to be a risk factor for early experimentation with tobacco $\mathrm{Hu}$ et al. 2008; Patton et al. 2006). Moreover, disruptive children have also been found more likely to affiliate with friends who engage in disruptive behaviors (Fite et al. 2008; Laird et al. 2001; Vitaro et al. 2007). It may therefore be the child's behavioral problems that predict early 
tobacco experimentation, possibly via the affiliation with disruptive friends. For instance, it has been shown that early behavioral regulation difficulties predict maladaptive social relations and that the consequences of these behavioral problems are the driving force in the link to substance abuse disorders (Fite et al. 2008; Tarter et al. 1999). Apart from disruptiveness, symptoms of ADHD are thought to put children at risk for tobacco experimentation (Elkins et al. 2007; Upadhyaya et al. 2002; Upadhyaya et al. 2005). ADHD-related impulsiveness may make children prone to experiment, while they also have problems of understanding and considering the long-term consequences of smoking (Wilson and Levin 2005). Thus, disruptive behavior problems and symptoms of ADHD should be controlled for when studying the link between friends' disruptiveness and children's tobacco experimentation. This is especially the case for the present study as the GBG has show to reduce both children's disruptive behavior problems and symptoms of ADHD (Dolan et al. 1993; Ialongo et al. 2001; Ialongo et al. 1999; Kellam et al. 1994; van Lier et al. 2004; van Lier et al. 2005b; Witvliet et al. 2009). Therefore, it might be that the reductions in children's disruptiveness and ADHD symptoms rather than reductions in their friends' disruptiveness account for a reduced likelihood of GBG children to experiment with tobacco. In fact, in a previous study, it was found that reductions in symptoms of ADHD mediated the program's effect on tobacco experimentation over ages 10-11 years (Huizink et al. 2009).

Besides child behavioral risks, having - even fewfriends who smoke, and having parents who smoke has been linked with children's smoking behavior (Kobus 2003; Mowery et al. 2004; Prokhorov et al. 2006). Therefore, in order to examine whether friends' disruptiveness is indeed a risk factor for children's tobacco experimentation, we have to control for the behavioral tendencies of the children themselves and the possible influences of friends' and parental smoking.

\section{The Present Study}

The aim of this study is to test the role of friends' disruptiveness from age 7-10 years in the development of tobacco experimentation over the ages 10-13 years using a randomized controlled trial (RCT). RCTs have been proposed as a unique design for testing the role of social factors in developmental psychopathology (Hinshaw 2002; Kellam and Rebok 1992; Rutter et al. 2001). We hypothesized that reduced rates of friends' disruptiveness, as found among children who followed the GBG curriculum compared to controls, mediated the lower rates of tobacco experimentation among GBG children. In studying this link, we will take possible sex-differences into account as boys are more likely to affiliate with antisocial friends than girls (van Lier et al. 2005a, b, Vitaro et al. 2007). In addition, we tested whether the results held when controlling for children's co-existing disruptive behavior and symptoms of ADHD, and for having friends or parents who smoke.

\section{Methods}

\section{Participants}

Participants were recruited from 13 elementary schools in Rotterdam and Amsterdam, the Netherlands. Initially, 744 children were eligible for inclusion and for 666 children informed consent from parents or parent substitutes was obtained ( $90 \%$ participation rate). The mean age of these children was 6.9 years $(S D=0.6)$ at baseline, $52 \%$ of the sample were males. Sixty-nine percent of the children were from Dutch descent, 10\% Turkish, 9\% Moroccan, 5\% Surinam/Dutch Antillean, and 7\% from other ethnic groups. Thirty-six percent of the children were from a family with low socio-economic status (SES), which closely resembled the general Dutch population (32\%; Statistics Netherlands 2006).

Assessments of tobacco experimentation over the ages 10-13 years were available for 525 children of the original sample (79\%). However, because of our focus on the prevention of early tobacco experimentation, we selected those children for whom data on tobacco experimentation were available from age 10 years onwards ( 477 children; $72 \%$ of original sample). Because of our focus on the role of friends, we only included participants who had reciprocated friendships over the period of age 7-10 years, reducing the study sample to 433 children. (Reciprocated friendships indicated that both the participant and the friends agreed on their relationship as a friendship.) Not being part of the study sample was not related to intervention condition $\left(\mathrm{GBG} / \mathrm{control} ; \chi^{2}(1)=0.13, p=\right.$ $0.72)$ or to the child's gender $\left(\chi^{2}(1)=1.71, p=19\right)$, but was related to low SES $\left(\chi^{2}(1)=31.89, p<0.01\right)$. Exclusion from this study was not related to levels of disruptiveness exhibited by the friends of the participants in first grade ( $F$ $(1,634)=0.16, p=0.69)$.

Of the 433 children who were followed in this study (seven repeated assessments), $32 \%$ had missing data on one or more assessments, with just $6 \%$ missing data on two or more assessments. Missing assessments were not related to the intervention status $\left(\mathrm{GBG} /\right.$ control; $\left.\chi^{2}(1)=0.79, p=0.37\right)$ child's gender $\left(\chi^{2}(1)=3.34, p=0.08\right)$, or to levels of tobacco experimentation at age 10 years $\left(\chi^{2}(1)=0.18, p=\right.$ $0.67)$, but they were positively related to friends' disruptiveness in first grade $(F(1,428)=13.33, p<0.01)$. 
Procedures and Study Design

Children were first assessed in the spring of first grade elementary school. After this baseline assessment, classes within each school were randomly assigned to the GBG or to a control condition, resulting in $56 \%$ of the participants receiving the GBG program. The GBG was implemented during second and third grade (ages 7-9 years). Children were then followed-up annually over the elementary school period, which ends in grade 6 (age 12 years) in the Netherlands. The final assessment was at age 13 years, when children had transitioned to high school. In the Netherlands this means that children move to a variety of different schools.

Data collection was always executed in the spring of each school year. In the spring of grades 1-4, peer nominations were obtained through face-to-face interviews by trained interviewers. Self-reports of substance use were collected from grade 4 (age 10 years) onwards. The questionnaire was part of a larger booklet and was filled out in the classroom, supervised by two trained supervisors of the research team. The children were told that their answers would be confidential and that they did not have to answer any of the questions if they did not want to. Teachers were not present in the classroom while the children were filling out the questionnaires.

At age 13 years, the questionnaire for the assessment of substance use was part of a larger booklet used for the young adolescence follow-up assessments, which was sent to the participants and returned by mail. Children always received a small token reward for their participation.

Teacher assessments were collected each school year in the spring, either through questionnaires or via a faceto-face interview (see Measures section). Teachers received gift certificates or token rewards, such as a box of chocolates for their participation.

\section{Preventive Intervention}

The Good Behavior Game (Barrish et al. 1969; Dolan et al. 1989) is a classroom-based intervention aimed at reducing disruptive behavior. The GBG was adapted for use in the Netherlands (Van der Sar 2002; Van der Sar and Goudswaard 2001). The program is described in detail elsewhere (van Lier et al. 2004). In short, teachers and students choose positively formulated class-rules, which are accompanied by pictograms. Based on behavioral observations of rule-breaking classroom behaviors, teachers assign children to one of three/four teams while ascertaining that teams contain an equal number of disruptive and nondisruptive children. Positive peer relations are facilitated by the GBG by stimulating children to collaborate with team members, by encouraging children to support each other in behaving appropriately, and by systematically rewarding compliance to positively formulated class rules within teams. Each team receives a number of cards. Teachers take a card when a student violates a rule. Teams are rewarded when at the end of the game at least one card remains.

The GBG was implemented in three stages. In the introduction stage, the GBG was played for three times a week during $10 \mathrm{~min}$. In the expansion stage, the GBG was expanded in time, settings, and behaviors targeted. Rewards were delayed till the end of the week and month. In the generalization phase, emphasis was on explaining children that the GBG rules always apply. Children received compliments for appropriate behavior. GBG-sessions were used as booster sessions.

Each intervention year, teachers participated in three afternoons of training, and were coached in their classroom during ten 60 -min classroom observations by the school advisory services. External school advisors evaluated implementation fidelity at the schools. Control-condition teachers were monitored in not implementing the GBG. Over the 2-year intervention period, the GBG was played on average 116.28 times $(S D=45.59)$ per class for a total of $8162 \mathrm{~min}(136 \mathrm{~h})(S D=4781 \mathrm{~min}$.). In five classes in which the GBG was implemented incompletely (teachers did not move on to the expansion phase), the game was nonetheless played on average 63.20 times $(S D=21.62)$. In the remaining 13 classes, in which the program was implemented completely, the mean number of sessions was 139.69 $(S D=34.11)$. Although some variation in implementation fidelity was found, we judged it applicable to use an intentto-treat approach in the further analyses.

\section{Measures}

Preferred peers' disruptive behavior (henceforth referred to as $\mathrm{PP}_{\mathrm{DB}}$ ) was used as an indication of friends' disruptive behavior. Only reciprocated identifications of preferred peers were used, which indicated that the nominated preferred peer, in turn, also identified the participant as one of the classmates preferred peer. The $\mathrm{PP}_{\mathrm{DB}}$ score at each assessment was computed in three steps. First, all children were asked to indicate the three classmates of either sex they liked most. These liked-most indications for each child were used to identify the preferred peers of each child. Second, disruptive behavior of all children in the class was assessed via a peer nominations procedure. Each child in the class was asked to nominate all classmates of either sex that fit each of two descriptions, 'says mean thing to peers', and 'is disruptive' (see below for a more detailed description of the assessment of children's disruptive behavior). Third, using this score of each child in the class, it was then possible to assess the (reciprocal) preferred peers' disruptive behavior in the same way as for the 
participants themselves. When participants had more than one preferred peer, the average of their preferred peers' disruptive behavior was used.

Experimentation with Tobacco Children filled out the selfreport Substance Use Questionnaire (SUQ; Erasmus MC 2000) annually from age 10-13. Cigarette experimentation was scored on a 7-point scale ranging from 0 (did not smoke at given age) to 7 (smoked more than 20 cigarettes per day). Of those who reported cigarette experimentation, the majority reported smoking less than one cigarette per week. We therefore focused on experimentation versus noexperimentation $(0=$ no tobacco experimentation at given age, $1=$ tobacco experimentation, which included all scores ranging from 'smoking one cigarette or less a week' to 'smoked more than 20 cigarettes per day'). The percentage of children experimenting with tobacco was 5.3, 10.6, 12.7, and 14.1 at ages 10-13 years, respectively. These percentages are in accordance with those reported for youth of similar age from the general Dutch population (Monshouwer et al. 2004).

\section{Covariates/Control Variables}

Percentage of preferred peers who experimented with tobacco (as an indication of friends who smoke) was assessed at age 10 and 12 years. The assessment of preferred peers of participants is described above (step one in the computation of $\mathrm{PP}_{\mathrm{DB}}$ ). Tobacco experimentation was assessed via the SUQ for all children in the class. Using this score, a tobacco experimentation score was computed for each of the participants' preferred peer. The percentage of preferred peers who experimented with tobacco was computed by dividing the number of preferred peers who reported tobacco experimentation by the total number of preferred peers at ages 10 and 12 years.

Parental smoking was assessed during a telephone interview when children were 10 years old. At the time of the assessment, parents were asked if they currently smoked. Current smoking was defined as a dichotomized variable: 0 ("no") if they did not currently smoke and 1 ("yes") if they did.

Children's levels of disruptiveness from ages 7-10 years were assessed towards the end of each school year by asking each child to nominate all classmates of either sex who fit each of the two descriptions, 'says mean things to peers', and 'is disruptive'. The two scores were divided by the number of children in the class minus one (nominating oneself was not allowed) and then summed to a total score. Cronbach's alphas for the total score ranged from 0.86 to 0.90 over the four assessments.
Children's symptoms of ADHD were assessed by teacher ratings. In first and third grade (age 7 and 9 years), ADHD symptoms were assessed over the last 2 months by means of the Teacher's Report Form (TRF/6-18; Achenbach 1991; Verhulst et al. 1997). The 13 items of the DSM-IV oriented symptoms of ADHD scale were used (Achenbach et al. 2001). Items included information on inattention (for example, 'this child has difficulty concentrating') as well as on behavioral impulsivity and hyperactivity (for example, 'this child is impulsive', 'this child talks out of turn', 'this child finds it hard to sit still'). The 13 item scores were summed to a total ADHD score. Cronbach's alphas ranged from 0.90 to 0.91 over the assessments.

In second and third grade (ages 8 and 9 years), teachers were interviewed with the Problem Behavior at School Interview (PBSI; Erasmus MC 2000). The PBSI is a 32item interview assessing disruptive and shy/withdrawn behavior. Teachers rated the child's behavior on a 5-point Likert scale. The ADHD problem scale of the PBSI was used in this study. The ADHD scale consists of 8 items, focusing on inattention, impulsivity, and hyperactivity. Items included 'this child has difficulty concentrating' and 'this child is impulsive'. The correlation coefficient between two teachers who rated the same children reflecting interrater reliability was $r=0.45 \quad(n=126 ; p<0.01)$. Cronbach's alpha was 0.90 at both assessments.

Intervention status was coded as $0=$ control, $1=G B G$ according to grade 2 (age 7 years) assignment. Over the 2 year period of the intervention (age 7-9 years) 17 children moved from a control group to an intervention group. These children were included as intervention children in the analyses.

Child's gender $(0=$ female, $1=$ male $)$ was included as a control variable.

\section{Statistical Analyses}

The analyses were executed in three steps. In the first step, we analyzed the development of preferred peers' disruptive behavior $\left(\mathrm{PP}_{\mathrm{DB}}\right)$ using latent growth parameters, where the intercept reflects level differences, and the linear (and quadratic) term reflects time related increases or decreases in disruptive behavior of preferred peers (Muthén 1997). To account for the data structure in which data, as well as the randomization to intervention or control were nested within classes, a multilevel growth model was fitted. The growth parameters were regressed on intervention status (GBG vs. controls; between level) and male sex (within level), to study differential growth in preferred peers' disruptive behavior as a function of intervention, and gender. The intercept was parameterized at the last, age 10 year assessment, because we were interested in post-intervention effects in levels of $\mathrm{PP}_{\mathrm{DB}}$ as predictor of tobacco experimentation trajectories. 
In the second step we added the development of tobacco experimentation to the model (dual growth model). The growth parameters of tobacco experimentation were regressed on the growth parameters of $\mathrm{PP}_{\mathrm{DB}}$ as well as on intervention status. Standard errors were adjusted to account for the clustering of data within classrooms, using a sandwich estimator (Williams 2000). Mediation of GBG effects on tobacco experimentation by $\mathrm{PP}_{\mathrm{DB}}$ was tested in two ways. First, we tested whether the direct effect of GBG status on the growth parameters of tobacco experimentation became non-significant when accounting for the influence of $\mathrm{PP}_{\mathrm{DB}}$ (see Baron and Kenny 1986). Second, we estimated the joint significance of the indirect paths (path from GBG status to $\mathrm{PP}_{\mathrm{DB}}$ and path from $\mathrm{PP}_{\mathrm{DB}}$ to tobacco experimentation) (see MacKinnon et al. 2002).

In the third step, we tested whether the findings on the link between $\mathrm{PP}_{\mathrm{DB}}$ and tobacco experimentation would hold when accounting for friends' tobacco experimentation, parental tobacco use, and children's symptoms of ADHD. A graphical representation of the final model is in Fig. 1. All models were fit in Mplus version 5.1 (Muthén and Muthén 1998-2009). Over the seven repeated assessments,
$32 \%$ of cases had missing data on one or more assessments, with $6 \%$ missing data on two or more assessments. These occasional missing data were handled using Full Information Maximum Likelihood estimation. To explore whether the models fitted the data well, the chi-square statistic (nonsignificant test values indicate a good fit), the Comparative Fit Index and Tucker Lewis Index (CFI and TLI; acceptable fit values $>0.90$; Bentler 1990), and the root mean squared error of approximation (RMSEA; acceptable value $<0.08$; Browne and Cudeck 1993) were used.

\section{Results}

\section{Descriptive Statistics}

The correlations between the repeatedly assessed preferred peers' disruptive behavior scores $\left(\mathrm{PP}_{\mathrm{DB}}\right)$ ranged from 0.37 to 0.59 (all $p$ values $<0.01$ ). The means and standard deviations of preferred peers' disruptive behavior are shown in Table 1. Boys had preferred peers with higher levels of disruptive behavior than girls. Results also showed

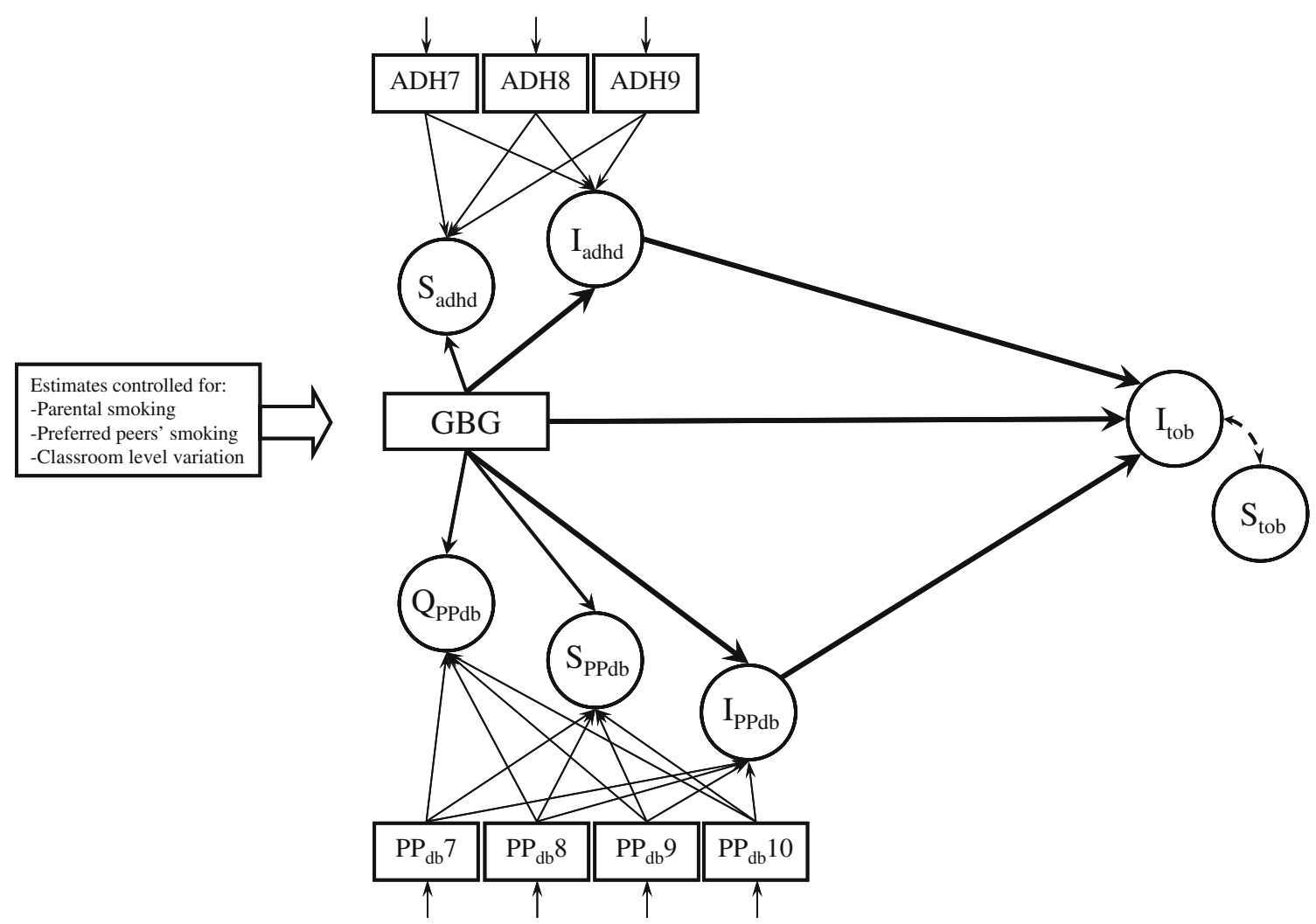

Fig. 1 Analyses model of mediation of preferred peers' disruptive behavior from age 7-10 and tobacco experimentation from age 10-13, while controlling for symptoms of ADHD from age 7-9 years, parental smoking and preferred peers' tobacco experimentation. For reasons of presentation, no path estimates from higher order growth parameters to the intercept of tobacco experimentation are printed. Those paths were however tested for 
Table 1 Means and standard deviations of preferred peers' disruptive behavior at ages 7 to 10 as a function of sex, intervention status and tobacco experimentation (age 10)

\begin{tabular}{|c|c|c|c|c|c|c|c|c|c|c|c|c|c|c|c|}
\hline \multirow[t]{4}{*}{ Age } & \multicolumn{4}{|l|}{ Sex } & \multicolumn{4}{|c|}{ Intervention status } & \multicolumn{4}{|c|}{ Tobacco experimentation } & \multicolumn{3}{|l|}{ Test } \\
\hline & \multirow{2}{*}{\multicolumn{2}{|c|}{$\frac{\text { Boys }}{n=233}$}} & \multirow{2}{*}{\multicolumn{2}{|c|}{$\begin{array}{l}\text { Girls } \\
n=200\end{array}$}} & \multirow{2}{*}{\multicolumn{2}{|c|}{$\begin{array}{l}\text { Control } \\
n=194\end{array}$}} & \multirow{2}{*}{\multicolumn{2}{|c|}{$\begin{array}{l}\text { GBG } \\
n=239\end{array}$}} & \multirow{2}{*}{\multicolumn{2}{|c|}{$\frac{\text { No }}{n=410}$}} & \multirow{2}{*}{\multicolumn{2}{|c|}{$\begin{array}{l}\text { Yes } \\
n=23\end{array}$}} & \multirow{3}{*}{$\begin{array}{l}\text { Sex } \\
F \\
F\end{array}$} & \multirow{3}{*}{$\begin{array}{l}\text { GBG } \\
F \\
F\end{array}$} & \multirow{3}{*}{$\begin{array}{l}\text { Tob. Exp. } \\
F\end{array}$} \\
\hline & & & & & & & & & & & & & & & \\
\hline & $M$ & $S D$ & $M$ & $S D$ & $M$ & $S D$ & $M$ & $S D$ & $M$ & $S D$ & $M$ & $S D$ & & & \\
\hline 7 & 0.36 & 0.24 & 0.19 & 0.16 & 0.28 & 0.22 & 0.28 & 0.23 & 0.26 & 0.22 & 0.28 & 0.23 & $45.68 * *$ & 0.01 & 0.18 \\
\hline 8 & 0.37 & 0.25 & 0.18 & 0.16 & 0.26 & 0.23 & 0.30 & 0.23 & 0.27 & 0.23 & 0.37 & 0.30 & $71.99 * *$ & 1.55 & $4.32 *$ \\
\hline 9 & 0.34 & 0.25 & 0.13 & 0.15 & 0.22 & 0.22 & 0.24 & 0.24 & 0.22 & 0.22 & 0.37 & 0.32 & $84.39 * *$ & 1.04 & $8.63 * *$ \\
\hline 10 & 0.27 & 0.24 & 0.11 & 0.16 & 0.24 & 0.27 & 0.16 & 0.17 & 0.18 & 0.20 & 0.35 & 0.32 & $50.99 * *$ & $9.75 * *$ & $12.41 * *$ \\
\hline
\end{tabular}

$\mathrm{GBG}=$ Good Behavior Game.

$*=p<0.05$

$* *=p<0.01$

that at age 10 years children who received the GBG intervention had preferred peers with lower disruptive behavior scores than controls.

The means and standard deviations of $\mathrm{PP}_{\mathrm{DB}}$ for children who reported experimentation with tobacco at age 10 years, compared to those who did not experiment, are also in Table 1. It shows that children who reported tobacco experimentation at age 10 years had higher $\mathrm{PP}_{\mathrm{DB}}$ scores than children who did not experiment with tobacco at ages 8,9 , and 10 years, but not at age 7 years.

\section{Experimentation with Tobacco from Age 10 to 13}

The impact of the GBG on tobacco experimentation has been described previously (van Lier et al. 2009). The percentages of controls vs. GBG children at ages 10, 11, 12, and 13, respectively, who reported experimentation with tobacco was $7.7 \%$ vs. $3.3 \%, 13.9 \%$ vs. $7.9 \%, 12.9 \%$ vs. $12.6 \%$, and $16.5 \%$ vs. $12.1 \%$.

To statistically analyze the impact of the GBG on the development of tobacco experimentation, a multilevel growth model for categorical data, with an intercept and linear term, was specified. The intercept was centered at the middle assessment (age 12; variance of intercept $=7.96, \mathrm{SE}=1.82$, $p<0.01$; slope $=0.48, \mathrm{SE}=0.26, p=0.06$ ). The growth parameters were regressed on intervention status (between levels). A significant effect of intervention status on the intercept was found $\beta=-0.06, p<0.01$. No significant effect of GBG status on the slope parameter was found. When fitting a multiple group model (males vs. females) to test for possible sex-differences, this effect of intervention appeared to be similar for boys and girls $\Delta \chi^{2}(1)=0.77, p=0.38$.

To test whether the level differences (effects on the intercept) were present at each assessment, the intercept was parameterized at ages 10,11 , and 13 years, respective- ly. The results showed significant intercept differences at all assessments; $\beta=-0.07, \beta=-0.06$, and $\beta=-0.04$ at ages 10 , 11 , and 13 , respectively. Together the results indicated that the rate of increase in tobacco experimentation over ages 10-13 years was similar across GBG and control-group children. However, GBG children had a lower probability of experimentation with tobacco over the studied period (see also van Lier et al. 2009).

Step 1: The Development of Preferred Peers' Disruptive Behavior from Age 7-10 Years

A multilevel growth model with an intercept, a linear, and a quadratic slope was fitted for the development of $\mathrm{PP}_{\mathrm{DB}}$. The intercept was parameterized at the last (age 10) assessment. The model had a good fit to the data: $\chi^{2}(7)=6.72, p=0.46$, $\mathrm{CFI}=1.00, \mathrm{TLI}=1.00, \mathrm{RMSEA}=0.00$; mean intercept $=0.21$, $\mathrm{SE}=0.02, p<01$, slope $=-0.05, \mathrm{SE}=0.02, p<0.05$, quadratic slope $=-0.01, \mathrm{SE}=0.01, p<0.05$; variance of intercept $=0.03$, $\mathrm{SE}=0.01, p<0.01 ;$ slope $=0.01, \mathrm{SE}=0.01, p<0.05$, quadratic slope $=0.002, \mathrm{SE}=0.001, p<0.05$. A graphical representation of the development of $\mathrm{PP}_{\mathrm{DB}}$ is given in Fig. 2.

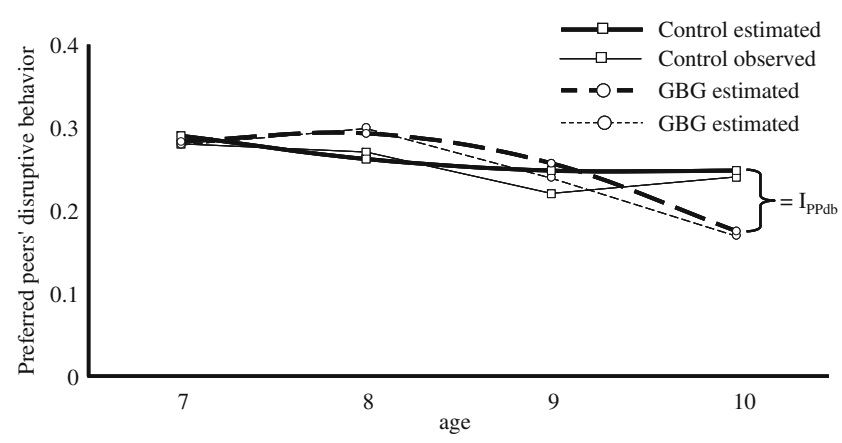

Fig. 2 The development of preferred peers' disruptive behavior from age $7-10$ for $\mathrm{GBG}$ and control group children. $\mathrm{GBG}=\mathrm{Good}$ Behavior Game 
At the within level, the growth parameters were regressed on male sex, while at the between level, the intercept growth parameter was regressed on intervention status. In the within level, only a significant effect of male sex was found on the intercept, $\mathrm{B}=0.16, \mathrm{SE}=0.02, \beta=0.52$, $p<01$. Results at the between level showed a significant intervention effect on the intercept: $\mathrm{B}=-0.80, \mathrm{SE}=0.04$, $\beta=-0.48, p<01$. With the intercept parameterized at the last assessment, this reflected significant level differences at age 10 years (1 year post intervention). This effect of intervention was found to be similar for boys and girls, $\Delta \chi^{2}(1)=0.27, p=0.60$. Because of our interest in postintervention levels of $\mathrm{PP}_{\mathrm{DB}}$, we focus on the intercept of $\mathrm{PP}_{\mathrm{DB}}$ in the remainder of the results section.

Having established intervention effects of the GBG resulting in reductions in preferred peers' disruptive behavior and lower levels of tobacco experimentation, we moved on to testing for mediation of tobacco experimentation by preferred peers' disruptive behavior.

Step 2: Mediation of Tobacco Experimentation by Preferred Peers' Disruptive Behavior

We then specified a model in which growth of $\mathrm{PP}_{\mathrm{DB}}$ and growth in tobacco experimentation were combined. To test for possible mediation between the GBG status and tobacco experimentation by $\mathrm{PP}_{\mathrm{DB}}$, the growth parameters of tobacco experimentation were regressed on the growth parameters of $\mathrm{PP}_{\mathrm{DB}}$.

The growth parameters of tobacco experimentation were also regressed on intervention status (control vs. GBG). The link between the intercept of $\mathrm{PP}_{\mathrm{DB}}$ with the slope of tobacco experimentation was not significant, which suggests that the level of peers' disruptive behaviors at age 10 was not associated with increases or decreases in children's tobacco experimentation over time. Also, no significant links between the linear or quadratic slope term of $\mathrm{PP}_{\mathrm{DB}}$ with either the intercept or slope of tobacco experimentation were found. This suggests that the post-intervention level differences in $\mathrm{PP}_{\mathrm{DB}}$ (age 10) between $\mathrm{GBG}$ and control group children explained the level differences in tobacco experimentation at age 12 (= age of centering of intercept of tobacco experimentation). The non-significant paths between the growth parameters were therefore deleted from the model. This final model had an excellent fit to the data: $\chi^{2}(10)=10.56, p=0.39, \mathrm{CFI}=1.00, \mathrm{TLI}=.1 .00$, RMSEA $=0.01$. The model explained $13.2 \%$ of the variance of the intercept of tobacco experimentation.

Results are depicted in Fig. 3. By including $\mathrm{PP}_{\mathrm{DB}}$ in the model, the previously found direct effect of GBG status on the intercept of tobacco experimentation was no longer significant: $\mathrm{B}=-0.12, \mathrm{SE}=0.14, \beta=0.07, p=0.41$, which suggests mediation (Baron and Kenny 1986). Moreover, both path estimates that comprise the mediation link (path

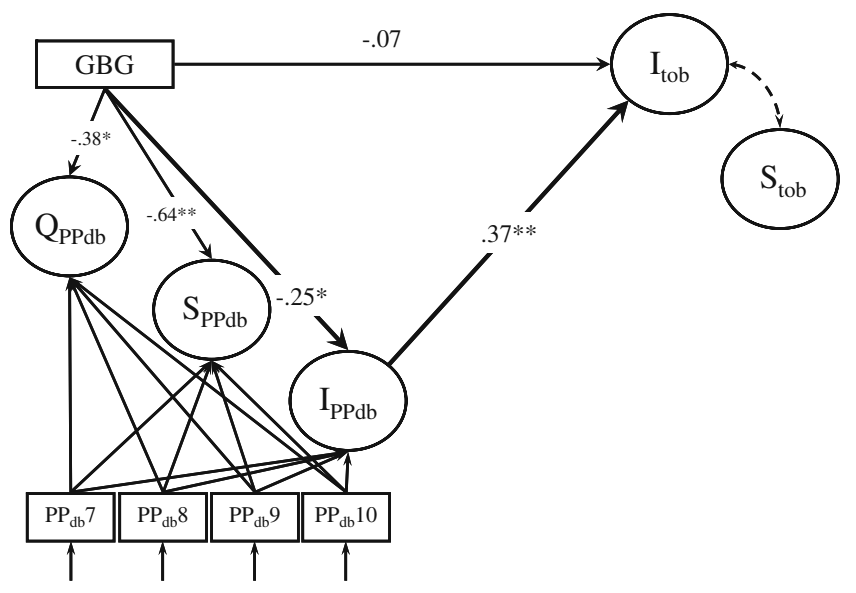

Fig. 3 Results from the mediation model of preferred peers' disruptive behavior from age 7-10 and tobacco experimentation from age 10-13. Path estimates reflect standardized regression coefficients. For reasons of presentation, non-significant regression paths are not printed. $\mathrm{GBG}=$ Good Behavior Game. $\mathrm{I}=$ Intercept. $\mathrm{S}=$ Linear Slope. $\mathrm{Q}$ $=$ Quadratic Slope. $\mathrm{PPdb}=$ Preferred Peer Disruptive Behavior. Tob= Tobacco Experimentation. $*=p<0.05$. $* *=p<0.01$

from intervention status to the intercept of $\mathrm{PP}_{\mathrm{DB}}$, and the path from the intercept of $\mathrm{PP}_{\mathrm{DB}}$ to the intercept of tobacco experimentation) were significant. We therefore also estimated the significance of the indirect path of GBG to tobacco experimentation via $\mathrm{PP}_{\mathrm{DB}}$. $\mathrm{A}$ trend towards significance was found for this indirect path: $\mathrm{B}=-0.15$, $\mathrm{SE}=0.09, \beta=-0.09, p=0.09$. When centering the intercept of tobacco experimentation at ages 10,11 , or 13 , results were $\beta=-0.09, \beta=-0.09$, and $\beta=-0.10$, respectively (all $p$ values $=0.09)$. This suggested that the trend toward significance for the indirect pathway from $\mathrm{PP}_{\mathrm{DB}}$ to level differences in tobacco experimentation was found at each assessment of tobacco experimentation.

We then tested whether the link between preferred peer disruptive behavior and tobacco experimentation was not accounted for by the disruptive behavior exhibited by the children themselves. Note that participants and friends were in the same classroom, and disruptive behavior scores of both friends and participants themselves were based on the same peer nominations scores. Thus, not having disruptive friends, but rather the disruptive behavior of children themselves may in fact account for the meditational link from GBG to tobacco experimentation via friends' disruptiveness. We therefore added the assessments of children's peer nominated disruptive behavior over the ages $7-10$ years as time-varying covariates to the model. Specifically, in this model the friends' disruptive behavior scores were regressed on the child's disruptive behavior scores to control the friends' disruptive behavior score for possible shared variance with children's disruptiveness. When controlling for children's disruptiveness, the previously found results remained the same: $\mathrm{B}=-0.18, \mathrm{SE}=$ $0.11, \beta=-0.11, p=0.09$. 
Finally, we tested whether the strengths of the associations of the paths that comprise the indirect pathway (GBG to intercept $\mathrm{PP}_{\mathrm{DB}}$, intercept of $\mathrm{PP}_{\mathrm{DB}}$ to intercept of tobacco experimentation) were similar across sex. Results showed that the indirect path was similar across males and females, $\Delta \chi^{2}(2)=0.61, p=0.74$.

Step 3: Controlling for Parental and Friends' Smoking and Children's ADHD Symptoms

Twelve percent of the preferred peers of the children who experimented with tobacco at age 10 years reported experimentation with tobacco themselves. This was $5 \%$ for the preferred peers of children who did not experiment with tobacco. Of the children who experimented with tobacco, $47 \%$ of the parents smoked. This was $39 \%$ for children who did not experiment with tobacco. Also, as stated, GBG children had lower levels of symptoms of ADHD, which were found to mediate the effect of the program on tobacco experimentation at ages 10 and 11 years (Huizink et al. 2009).

We therefore tested whether our results would hold when controlling for the possible influence of friends or parents who smoke and for ADHD symptoms exhibited by the child. This model is depicted in Fig. 1. The path from the intercept of preferred peers' disruptive behavior to the intercept of tobacco experimentation was controlled for smoking of preferred peers and parents. In addition, we added the development of symptoms of ADHD from ages 7-9 years to the model. Two measures of ADHD symptoms were used (TRF and PBSI), with missing data on either measurement handled as missing by design. At age 9 years, both instruments were completed. To account for this missing-by-design, a latent variable was considered for each of the time-points. Indicators for these latent variables were the total ADHD symptom scores derived from the TRF and PBSI at the given time-points. The factor loading of the TRF on the latent variables at each time-point was set at 1 by default; the factor loading for PBSI was held equal across time, and the measurement intercepts were constrained to be equal across time for both the TRF and PBSI scores (see also Huizink et al. 2009). The intercept of ADHD symptoms was parameterized at the last assessment.

The results of this model are shown in Table 2. The model had a good fit to the data, $\chi^{2}(15)=29.26, p<0.05$, CFI/TLI $=0.93 / 0.93$, RMSEA $=0.04$. The results in the top portion of Table 2 show that the direct path estimates remained similar when compared to those for the model which did not control for parental and preferred peers' smoking and ADHD symptoms. Also the trend toward significance of the indirect path of $\mathrm{GBG}$ to tobacco experimentation via $\mathrm{PP}_{\mathrm{DB}}$ remained: $\mathrm{B}=-0.14, \mathrm{SE}=0.08$, $\beta=-0.09, p=0.09$.

The results for the effect of the pathway of intervention status, via ADHD symptoms to tobacco experimentation
Table 2 Good behavior game intervention, preferred peers' disruptive behavior and tobacco experimentation when controlling for friends' and parental smoking, and children's symptoms of ADHD

\begin{tabular}{lccc}
\hline Path & $B$ & $S E$ & $\beta$ \\
\hline $\mathrm{GBG} \rightarrow \mathrm{I}_{\text {tob }}$ & -0.06 & 0.14 & -0.04 \\
Mediator: Preferred peer's disruptiveness & & \\
$\mathrm{GBG} \rightarrow \mathrm{I}_{\mathrm{PPdb}}$ & -0.08 & 0.04 & $-0.24^{*}$ \\
$\mathrm{I}_{\mathrm{P} \text { db }} \rightarrow \mathrm{I}_{\text {tob }}$ & 1.66 & 0.52 & $0.35^{*}$ \\
$\mathrm{Indirect}$ path $\left(\mathrm{GBG} \rightarrow \mathrm{I}_{\mathrm{PPdb}} \rightarrow \mathrm{I}_{\text {tob }}\right)$ & -0.14 & 0.08 & $-0.09 \dagger$ \\
Mediator: $\mathrm{ADHD} \mathrm{symptoms}$ & & & \\
Intervention $\rightarrow \mathrm{I}_{\text {adhd }}$ & -1.12 & 0.47 & $-0.16^{*}$ \\
$\mathrm{I}_{\text {adhd }} \rightarrow \mathrm{I}_{\text {tob }}$ & 0.05 & 0.01 & $0.26^{*}$ \\
Indirect path $\left(\mathrm{GBG} \rightarrow \mathrm{I}_{\mathrm{PPdb}} \rightarrow \mathrm{I}_{\text {tob }}\right)$ & -0.06 & 0.03 & $-0.04^{*}$ \\
\hline
\end{tabular}

$\mathrm{GBG}=$ Good Behavior Game. $\mathrm{I}_{\mathrm{tob}}=$ Intercept Tobacco Experimentation. $\mathrm{I}_{\mathrm{PPdb}}=$ Intercept Preferred Peers' Disruptive Behavior. $\mathrm{I}_{\mathrm{adhd}}=$ Intercept ADHD symptoms.

$* p<0.05$

$\dagger p<0.10$

are in the lower portion of Table 2. No link between the slope parameter of ADHD symptoms and either the intercept or slope of tobacco experimentation was found. However, the link from the intercept of ADHD symptoms to the intercept of tobacco experimentation was significant. We also found a significant effect of intervention status on level differences (intercept) of ADHD symptoms. As a consequence the indirect path from GBG via ADHD symptoms to tobacco experimentation was significant: $\mathrm{B}=$ $-0.06, \mathrm{SE}=0.03, \beta=-0.04, p<0.05$.

\section{Discussion}

Having friends who engage in disruptive behavior has been reported to be a risk factor for childhood experimentation with tobacco. In this study, we tested the role of friends' disruptiveness in the development of tobacco experimentation, using a randomized controlled intervention study, the GBG. Although the GBG is a classroom management intervention, one of the pathways through which the GBG improves children's behavior is by improving peer relations (van Lier et al. 2005b; Witvliet et al. 2009), making it an attractive instrument to test our hypothesis.

With regard to the role of friends' disruptiveness on tobacco experimentation over age 10-13 years, the results of this study are not entirely unequivocal. Early experimentation with tobacco (at age 10 years) was more prevalent among children who had friends with higher levels of disruptiveness in the years prior to, or at age 10 . When testing the influence of the GBG intervention we 
found a reduction in children's experimentation with tobacco use. This effect of the GBG became nonsignificant when reductions in friends' disruptiveness were accounted for. This suggests that the effects of the GBG on tobacco use were mediated by its effects on friends' disruptiveness (Baron and Kenny 1986). However, in a second test for mediation in which the actual significance of the mediation path is estimated (MacKinnon et al. 2002), this indirect path from GBG to tobacco experimentation via friends' disruptiveness just failed to reach conventional levels of significance. A trend toward significance was found, however, indicating that mediation is plausible. Moreover, these results remained virtually unchanged when we controlled for having friends or parents who smoked, and when accounting for reductions in symptoms of ADHD as found among GBG children. It is also important to note that we used a very stringent method to test for the link between friends' disruptive behavior and tobacco experimentation. We studied whether reductions in friends' disruptiveness established by a RCT focusing - among other aspects - on improving peer relations, mediated the reductions in tobacco experimentation. Such a randomized controlled associated change design is a unique design to test developmental psychopathology (Hinshaw 2002; Kellam and Rebok 1992; Rutter et al. 2001). Nonetheless, with the low baseline levels of tobacco experimentation in childhood and consequently limited possibilities to reduce these values, it may be hard to find definite proof for mediation in this regard. Therefore, although not unequivocal, our result mostly confirm the hypothesis that having friends with lower levels of disruptiveness in elementary school may protect children from starting to experiment with tobacco use in the second half of elementary school.

This study also showed that reduced rates of friends' disruptiveness and reductions in ADHD symptoms each uniquely mediated the effects of the GBG on tobacco experimentation. These results thereby also extend previous results on the mediating role of child behavior characteristics (ADHD; Huizink et al. 2009) as decreases in peer risks also mediated reductions in tobacco experimentation. This suggests that a classroom management intervention aimed at structuring the classroom, and facilitating prosocial behavior and prosocial peer affiliation can be effectively used to prevent children from early experimentation with tobacco. Surely, the GBG did not prevent experimentation altogether. In fact, the rate of increase in experimentation among GBG children is similar to the rate in the control condition (van Lier et al. 2009). However, compared to controls GBG children had always lower levels of tobacco experimentation, which persisted over a 4 year developmental span, despite the similar rate of increase in both groups. Thus, although not decisive, it may be concluded that universal behavioral management strategies, such as the GBG can be used as a first step in the prevention of disruptive behavior problems and associated risks, such as risky peer affiliation. Because of the effects in these domains of risk, such programs may also prevent later developing risk behaviors, such as tobacco experimentation.

This study is not without limitations. First, all children in this study received a general informative program on the prevention of substance use, including tobacco experimentation, in fifth and sixth grade (ages 11 and 12 years) elementary school. In the Netherlands, it is common that such programs are part of the normal curriculum of elementary schools. The research team provided all schools (GBG and controls) with the Health School and Drugs program (HSD; Jonkers et al. 1999). There was no control condition for HSD, making it impossible to statistically test for possible HSD effects on the findings of this study. However, reductions in tobacco experimentation were already present at age 10, thus prior to HSD and these relative differences between GBG children and controls persisted throughout the follow-up to age 13 years. Moreover, the mediators and control variables included in this study were assessed prior to HSD. This all suggests that the HSD did not affect the results as presented here. Second, no peer relations outside the classroom were considered. Elementary school children typically have friends within the classroom, even when friendship choices outside the classroom are allowed (Kupersmidt et al. 1995). As friendships were limited within classes, and classes as a whole received the GBG, our results may imply that being in a context in which peers are less disruptive, protects individuals from tobacco-experimentation. Our results however do not necessarily imply that because of the GBG, children select less disruptive friends, which, in turn explains why they are lower on tobacco-experimentation. For such a conclusion, friendship selection of peers from classes who did not receive the GBG would have been needed. Also we did not ask children about their actual friendships, but rather about peers they preferred, which may not necessarily reflect friendships. However, reciprocated preferred peers' scores were used in this study. Such scores indicate mutual preference, which closely resembles actual friendships. A third limitation is that we did not study micro processes of friends' influence. We found support that having friends who engage in disruptive behavior is a risk factor in the pathway to tobacco experimentation. However, micro processes, through which friends may actively influence children's drift towards tobacco experimentation, such as modeling, reinforcing risky behavior such as tobacco experimentation, or even making cigarettes available, regardless of whether they actually smoked themselves, were not studied. Fourth, although our results suggested that the links between 
preferred peers' disruptive behavior and tobacco experimentation were similar across sexes, the power to detect possible sex-differences may have been limited. Fifth, excluded children from this study were more likely to be of low SES families. The results should therefore be interpreted keeping this in mind. Finally, despite our test on the influence of friends via a randomized controlled design, no causal conclusions can be drawn from this study. Although we did run a number of tests to study whether our findings would hold, possible non-included variables may nonetheless account for the association.

The results of this study have implications for research on the development of psychopathology and tobacco experimentation. Our results suggested that having friends who engage in disruptive behavior may create a context in which children are more likely to start experimenting with tobacco early. This link persisted even when smoking of friends was accounted for. This suggests that the study of influence of peers who smoke should also take into account the (possibly previous) influence of disruptive behavior of these children. The results also demonstrate the power of early prevention. Not only can early, easily implementable universal programs prevent children's disruptive behavior problems, they can also reduce children's risks through the facilitation of prosocial, low risk peer relations. The results of this study showed that the reduced risk from the peer context may place children at lower risk for tobacco experimentation already at the age of 10 years, an effect that shows to persist into early adolescence.

Open Access This article is distributed under the terms of the Creative Commons Attribution Noncommercial License which permits any noncommercial use, distribution, and reproduction in any medium, provided the original author(s) and source are credited.

\section{References}

Achenbach, T. M. (1991). Manual for the Teacher's Report Form and 1991 Profile. Burlington: University of Vermont, Department of Psychiatry.

Achenbach, T. M., Dumenci, L., \& Rescorla, L. A. (2001). Ratings of relations between DSM-IV diagnostic categories and items of the $C B C L / 6-18$, TRF, and YSR. Burlington: University of Vermont, Research Center for Children, Youth, \& Families.

Baron, R. M., \& Kenny, D. A. (1986). The moderator-mediator variable distinction in social psychological research: conceptual, strategic, and statistical considerations. Journal of Personality and Social Psychology, 51, 1173-1182.

Barrish, H. H., Saunders, M., \& Wolfe, M. D. (1969). Good Behavior Game: effects of individual contingencies for group consequences and disruptive behavior in the classroom. Journal of Applied Behavior Analysis, 2, 119-124.

Bentler, P. M. (1990). Comparative fit indexes in structural models. Psychological Bulletin, 107, 238-246.
Boivin, M., Vitaro, F., \& Poulin, F. (2005). Peer relationships and the development of aggressive behavior in early childhood. In R. E. Tremblay, W. W. Hartup, \& J. Archer (Eds.), Developmental origins of aggression (pp. 376-397). New York: Guilford.

Browne, M. W., \& Cudeck, R. (1993). Alternative ways of assessing model fit. In K. A. Bollen \& J. S. Long (Eds.), Testing structural equation models (pp. 136-162). Newbury Park: Sage.

Clark, D. B. (2004). The natural history of adolescent alcohol use disorders. Addiction, 99(Suppl 2), 5-22.

Costello, E. J., Erkanli, A., Federman, E., \& Angold, A. (1999). Development of psychiatric comorbidity with substance abuse in adolescents: effects of timing and sex. Journal of Clinical Child Psychology, 28, 298-311.

Dishion, T. J., \& Owen, L. D. (2002). A longitudinal analysis of friendships and substance use: bidirectional influence from adolescence to adulthood. Developmental Psychology, 38, 480 491.

Dolan, L. J., Jaylan, T., Werthamer, L., \& Kellam, S. (1989). The good behavior game manual. Baltimore: The Johns Hopkins Prevention Research Center.

Dolan, L. J., Kellam, S. G., Brown, C. H., Werthamer-Larsson, L., Rebok, G. W., Mayer, L. S., et al. (1993). The short-term impact of two classroom-based preventive interventions on aggressive and shy behaviors and poor achievement. Journal of Applied Developmental Psychology, 14, 317-345.

Elkins, I. J., McGue, M., \& Iacono, W. G. (2007). Prospective effects of attention-deficit/hyperactivity disorder, conduct disorder, and sex on adolescent substance use and abuse. Archives of General Psychiatry, 64, 1145-1152.

Erasmus MC. (2000). Problem behavior at school interview. Rotterdam: Department of Child and Adolescent Psychiatry.

Fergusson, D. M., Swain-Campbell, N. R., \& Horwood, L. J. (2002). Deviant peer affiliations, crime and substance use: a fixed effects regression analysis. Journal of Abnormal Child Psychology, 30, 419-430.

Fite, P. J., Colder, C. R., Lochman, J. E., \& Wells, K. C. (2008). The relation between childhood proactive and reactive aggression and substance use initiation. Journal of Abnormal Child Psychology, $36,261-271$.

Furr-Holden, C. D., Ialongo, N. S., Anthony, J. C., Petras, H., \& Kellam, S. G. (2004). Developmentally inspired drug prevention: middle school outcomes in a school-based randomized prevention trial. Drug and Alcohol Dependence, 73, 149-158.

Hinshaw, S. P. (2002). Intervention research, theoretical mechanisms, and causal processes related to externalizing behavior patterns. Development and Psychopathology, 14, 789-818.

Hoffman, B. R., Sussman, S., Unger, J. B., \& Valente, T. W. (2006). Peer influences on adolescent cigarette smoking: a theoretical review of the literature. Substance Use \& Misuse, 41, 103-155.

Hu, M. C., Muthen, B., Schaffran, C., Griesler, P. C., \& Kandel, D. B. (2008). Developmental trajectories of criteria of nicotine dependence in adolescence. Drug and Alcohol Dependence, 98, 94104.

Huizink, A. C., van Lier, P. A., \& Crijnen, A. A. (2009). Attention deficit hyperactivity disorder symptoms mediate early-onset smoking. European Addiction Research, 15, 1-9.

Ialongo, N. S., Werthamer, L., Kellam, S. G., Brown, C. H., Wang, S., \& Lin, Y. (1999). Proximal impact of two first-grade preventive interventions on the early risk behaviors for later substance abuse, depression, and antisocial behavior. American Journal of Community Psychology, 27, 599-641.

Ialongo, N. S., Poduska, J., Werthamer, L., \& Kellam, S. (2001). The distal impact of two first-grade preventive interventions on conduct problems and disorder in early adolescence. Journal of Emotional and Behavioral Disorders, 9, 146-160. 
Jonkers, R., De Weerdt, I., Nierkens, V., \& Jongkind, S. (1999). De gezonde school en genotmiddelen 1995-98. Eindevaluatie [The Healthy School and Drugs 1995-98. Final evaluation]. Haarlem: ResCon.

Kellam, S. G., \& Rebok, G. W. (1992). Building developmental and etiological theory through epidemiologically based preventive intervention trials. In R. E. Tremblay \& J. McCord (Eds.), Preventing antisocial behavior: Interventions from birth through adolescence (pp. 162-195). New York: Guilford.

Kellam, S. G., \& Anthony, J. C. (1998). Targeting early antecedents to prevent tobacco smoking: findings from an epidemiologically based randomized field trial. American Journal of Public Health, $88,1490-1495$.

Kellam, S. G., Rebok, G. W., Ialongo, N., \& Mayer, L. S. (1994). The course and malleability of aggressive behavior from early first grade into middle school: Results of a developmental epidemiologically - based preventive trial. Journal of Child Psychology and Psychiatry, 35, 259-281.

Kellam, S. G., Brown, C. H., Poduska, J. M., Ialongo, N. S., Wang, W., Toyinbo, P., et al. (2008). Effects of a universal classroom behavior management program in first and second grades on young adult behavioral, psychiatric, and social outcomes. Drug and Alcohol Dependence, 95(Suppl 1), S5-S28.

Kobus, K. (2003). Peers and adolescent smoking. Addiction, 98(Suppl 1), $37-55$.

Korhonen, T., Huizink, A. C., Dick, D. M., Pulkkinen, L., Rose, R. J., \& Kaprio, J. (2008). Role of individual, peer and family factors in the use of cannabis and other illicit drugs: a longitudinal analysis among Finnish adolescent twins. Drug and Alcohol Dependence, 97, 33-43.

Kupersmidt, J. B., Burchinal, M., \& Patterson, C. J. (1995). Developmental patterns of childhood peer relations as predictors of externalizing behavior problems. Development and Psychopathology, 7, 825-843.

Laird, R. D., Jordan, K. Y., Dodge, K. A., Pettit, G. S., \& Bates, J. E. (2001). Peer rejection in childhood, involvement with antisocial peers in early adolescence, and the development of externalizing behavior problems. Development and Psychopathology, 13, 337-354.

MacKinnon, D. P., Lockwood, C. M., Hoffman, J. M., West, S. G., \& Sheets, V. (2002). A comparison of methods to test mediation and other intervening variable effects. Psychological Methods, 7, 83-104.

Monshouwer, K., Van Dorsselaer, S., \& Gorter, A. (2004). Jeugd en riskant gedrag: Kerngegevens uit het peilstationsonderzoek 2003. Roken, drinken, drugsgebruik en gokken onder scholieren vanaf tien jaar [Report in Dutch: Youth and risk behavior: Main findings from the Dutch National School Survey 2003]. Utrecht: Trimbos-instituut.

Mowery, P. D., Farrelly, M. C., Haviland, M. L., Gable, J. M., \& Wells, H. E. (2004). Progression to established smoking among US youths. American Journal of Public Health, 94, 331-337.

Muthén, B. (1997). Latent variable modeling with longitudinal and multilevel data. In A. Raftery (Ed.), Sociological methodology (pp. 453-480). Boston: Blackwell.

Muthén, L. K., \& Muthén, B. O. (1998-2009). Mplus User's guide. Fifth Edition. Los Angeles: Muthén \& Muthén.

Patton, G. C., Coffey, C., Carlin, J. B., Sawyer, S. M., \& Wakefield, M. (2006). Teen smokers reach their mid twenties. Journal of Adolescent Health, 39, 214-220.

Prokhorov, A. V., Winickoff, J. P., Ahluwalia, J. S., Ossip-Klein, D., Tanski, S., Lando, H. A., et al. (2006). Youth tobacco use: a global perspective for child health care clinicians. Pediatrics, 118, e890-903

Robinson, M. L., Berlin, I., \& Moolchan, E. T. (2004). Tobacco smoking trajectory and associated ethnic differences among adolescent smokers seeking cessation treatment. Journal of Adolescent Health, 35, 217-224.
Rutter, M., Pickles, A., Murray, R., \& Eaves, L. (2001). Testing hypotheses on specific environmental causal effects on behavior. Psychological Bulletin, 127, 291-324.

Snyder, J., Horsch, E., \& Childs, J. (1997). Peer relationships of young children: Affiliative choices and the shaping of aggressive behavior. Journal of Clinical Child Psychology, 26, 145156.

Snyder, J., Schrepferman, L., Oeser, J., Patterson, G., Stoolmiller, M., Johnson, K., et al. (2005). Deviancy training and association with deviant peers in young children: occurrence and contribution to early-onset conduct problems. Development and Psychopathology, 17, 397-413.

Statistics Netherlands. (2006). Beroepsbevolking beroepklassen [Working population classification of occupations]. Retrieved 15 June, 2009, from http://statline.cbs.nl/StatWeb/publication/?DM=SLNL\& $\mathrm{PA}=71812$ ned $\& \mathrm{D} 1=0 \& \mathrm{D} 2=0-1,8,29,62,83,91 \& \mathrm{D} 3=0-2 \&$ $\mathrm{D} 4=\mathrm{a} \& \mathrm{VW}=\mathrm{T}$

Storr, C. L., Ialongo, N. S., Kellam, S. G., \& Anthony, J. C. (2002). A randomized controlled trial of two primary school intervention strategies to prevent early onset tobacco smoking. Drug and Alcohol Dependence, 66, 51-60.

Tarter, R., Vanyukov, M., Giancola, P., Dawes, M., Blackson, T., Mezzich, A., et al. (1999). Etiology of early age onset substance use disorder: a maturational perspective. Development and Psychopathology, 11, 657-683.

Upadhyaya, H. P., Deas, D., Brady, K. T., \& Kruesi, M. (2002). Cigarette smoking and psychiatric comorbidity in children and adolescents. Journal of the American Academy of Child and Adolescent Psychiatry, 41, 1294-1305.

Upadhyaya, H. P., Rose, K., \& Wang, W. (2005). Attention-deficit/ hyperactivity disorder, medication and treatment, and substance use patterns among adolescents and young adults. Journal of Child and Adolescent Psychopharmacology, 5, 799-809.

Van der Sar, A. M. (2002). Licentiemap Taakspel voor schoolbegeleiders. Rotterdam: Pedologisch Instituut.

Van der Sar, A. M., \& Goudswaard, M. (2001). Docenthandleiding Taakspel voor basisonderwijs. Rotterdam: Pedologisch Instituut.

van Lier, P. A. C., \& Koot, H. M. (2008). Peer relationships. In R. Loeber, W. N. Slot, P. van der Laan, \& M. Hoeve (Eds.), Tomorrow's criminals: The development of child delinquency and effective interventions. Ashgate: Ashgate.

van Lier, P. A. C., Muthén, B. O., van der Sar, R. M., \& Crijnen, A. A. M. (2004). Preventing disruptive behavior in elementary schoolchildren: impact of a universal, classroom based intervention. Journal of Consulting and Clinical Psychology, 72, 467-478.

van Lier, P. A. C., Vitaro, F., Wanner, B., Vuijk, P., \& Crijnen, A. A. M. (2005a). Gender differences in the developmental links between antisocial behavior, friends' antisocial behavior and peer rejection in childhood: results from two cultures. Child Development, 76, 841-855.

van Lier, P. A. C., Vuijk, P., \& Crijnen, A. A. M. (2005b). Understanding mechanisms of change in the development of antisocial behavior: the impact of a universal intervention. Journal of Abnormal Child Psychology, 33, 521-535.

van Lier, P. A., Huizink, A., \& Crijnen, A. (2009). Impact of a preventive intervention targeting childhood disruptive behavior problems on tobacco and alcohol initiation from age 10 to 13 years. Drug and Alcohol Dependence, 100, 228-233.

Verhulst, F. C., Van der Ende, J., \& Koot, J. M. (1997). Handleiding voor de Teacher's Report Form. Rotterdam: Afdeling Kinder- en Jeugdpsychiatrie, Sophia Kinderziekenhuis/Academisch Ziekenhuis Rotterdam/Erasmus Universiteit Rotterdam.

Vitaro, F., Tremblay, R. E., \& Bukowski, W. M. (2001). Friends, friendships and conduct disorders. In J. Hill \& B. Maughan (Eds.), Conduct disorders in childhood and adolescence. Cam- 
bridge child and adolescent psychiatry (pp. 346-378). New York: Cambridge University Press.

Vitaro, F., Pedersen, S., \& Brendgen, M. (2007). Children's disruptiveness, peer rejection, friends' deviancy, and delinquent behaviors: a process-oriented approach. Development and Psychopathology, 19, 433-453.

Williams, R. L. (2000). A note on robust variance estimation for cluster-correlated data. Biometrics, 56, 645-646.
Wilson, J. J., \& Levin, F. R. (2005). Attention-deficit/hyperactivity disorder and early-onset substance use disorders. Journal of Child and Adolescent Psychopharmacology, 15, 751-763.

Witvliet, M., van Lier, P. A., Cuijpers, P., \& Koot, H. M. (2009). Testing links between childhood positive peer relations and externalizing outcomes through a randomized controlled intervention study. Journal of Consulting and Clinical Psychology, 77, 905-915. 